\title{
Blast Furnace Operation with 100\% Extruded Briquettes Charge
}

\author{
Aitber BIZHANOV, ${ }^{1) *}$ Ivan KURUNOV, ${ }^{2)}$ Yogesh DALMIA, ${ }^{3)}$ Bhagiratha MISHRA $^{3)}$ and Srishti MISHRA ${ }^{4)}$ \\ 1) J. C. Steele \& Sons, Inc., 710 South Mulberry Street, Statesville, NC 28677 USA. $\quad$ 2) Novolipetsk Steel (NLMK), pl. \\ Metallurgov 2, 398040, Lipetsk, Russia. \\ 3) Suraj Products Ltd., 770017, Sundargarh, Orissa, India.
}

4) IGIT, 759146 Sarang, Dhenkanal, Odisha.

(Received on September 2, 2014; accepted on October 20, 2014)

\begin{abstract}
Industrial stiff vacuum extrusion briquettes (BREX) producing line can efficiently provide for the smallscale blast furnace (BF) operation with $100 \%$ briquetted charge. Physical and metallurgical properties of the BREX are being investigated. A new effect of the non-linear strengthening of the BREX bonded with the combined Portland cement and Bentonite binder is described. Application of this combined binder results in the local maximum of the cold compressive strength of the BREX on third day of strengthening. Hot strength mechanism of the BREX is explained and was found to be related with creation of the metallized shell on their surface, sintering of the iron-containing particles and further creation of the metallicc phase surrounded by the silicates and ferrites. The addition of the iron ore fines to the BREX composition can improve their sintering during reduction thus helping to keep the integrity of the agglomerates. Results of the industrial operation of the small-scale BF with BREX are analyzed. The consumption of coke in the BF at $100 \%$ of BREX does not exceed $500 \mathrm{~kg} / \mathrm{t}$ compared with $680 \mathrm{~kg} / \mathrm{t}$ for the smelting without BREX.
\end{abstract}

KEY WORDS: extrusion briquette (BREX); stiff vacuum extrusion; small-scale blast furnace; coke rate; hot strength.

\section{Introduction}

For many years almost all major metallurgical plants in the world have accumulated millions of tons of blast furnace (BF) and steelmaking sludge, containing a significant amount of zinc oxides. The main method of such wastes recycling is their utilization at the sintering plant as the charge component for production of the sinter in quantities limited by the allowed zinc income to the blast furnace. The economic efficiency of this technology is provided by the partial replacement of the concentrate by the cheap sludge. However, the addition of such sludge in the sintering charge has a negative impact on the stability and quality of the sinter. More promising and environmentally friendly way of recycling of the sludge is their briquetting and subsequent use of briquettes in the BF. Thus, in addition to the improving of the stability and sinter's quality, carbon of the BF sludge in the briquettes is used as the reducing agent, whereas in the sinter process it almost does not work. A new concept in the BF sludge recycling includes the manufacture of briquettes from a mixture of sludge with iron ore concentrate and their utilization as the charge component of the blast furnace. The sludge is being removed from the sintering charge and the zinc incomes to the blast furnaces with briquettes do not exceed the established limits. The economic efficiency of this recycling technology is provided by the replacing of the expensive merchandise pellets, reduction of

* Corresponding author: E-mail: abizhanov@jcsteele.com

DOI: http://dx.doi.org/10.2355/isijinternational.55.175 the coke consumption by smelting of the carbon-containing briquettes and by the improvement of the sinter quality after the sludge removal from the charge of sinter plant.

At the beginning of the 20's of the last century the briquetting technology - the only agglomeration technology available at that time - has been widely used for the agglomeration of the iron ore fines and waste. For example, briquettes share in the charge of BF plant "West" in the Calbe (Germany) reached 30-40\%, and in the low-shaft BF plant Maxhütte (Germany) $-100 \%$. These briquettes were made from iron ore fines, coke and limestone dust. ${ }^{1)}$ In the BF plant of the Kuvshinovskyi metallurgical plant (Russia) the share of the briquettes in the charge was as high as $25 \%$. Briquettes in amounts up to 100 thousand tons per year were used in the BF of the Kerch and Taganrog metallurgical plants (Russia). ${ }^{2)}$ However, with the advent and development of high-productive iron ore and concentrates sintering method briquetting was not able to compete with this new technology due to the low capacity of the briquetting equipment.

At present time the agglomeration of the anthropogenic and natural iron containing substances by cold briquetting with the mineral or organic binders is obtaining increasing application in BF production. Three basic briquetting technologies are being applied - roller-pressing, vibropressing and the stiff vacuum extrusion. Application of the stiff vacuum extrusion for the agglomeration of fine ores and disperse metallurgical wastes has been mastered in the early 21 th century by the J. C. Steele\&Sons, Inc. (USA). This modern technology comprises pushing of the homogeneous 
wet (moisture contents 12-16\%) mix of the substances under the pressure of 3.0-3.5 Mpa through the die holes under the vacuum in the working chamber of the extruder. In 2012 the term BREX (briquettes of extrusion) has been introduced to distinguish these kinds of agglomerates from traditional briquettes. ${ }^{3)}$ The capacity of the industrial stiff extruders of J. C. Steele ranges from 15 to 115 tons per hour. The self-cost for the production of one ton of the BREX varies from 2 to 10 USD depending on the extrusion line capacity.

The first application of the auger extrusion for agglomeration of ore and metallurgical wastes took place in the 90ies of the 20th century when the industrial stiff extrusion briquetting line with the capacity of 20 tons per hour of the sludge and flue dust briquettes was commissioned at the Bethlehem Steel company (USA). ${ }^{4}$ These briquettes were melted in blast furnaces. The line was in operation till 1996 up to the cessation of main production.

\section{Industrial Stiff Extrusion Briquetting Line}

In April 2011 the industrial stiff extrusion line based on the Steele 25 Extruder for the production of the sludge, BF dust and iron ore fines briquettes for the small-scale BF was commissioned in Rourkela (West Bengali, India). ${ }^{5)}$ The capacity of this line is 20 tons per hour, or an average 6000 tons per month with two shifts per day working schedule and 20 working days per month, which fully meets the requirements of the $\mathrm{BF}$ in agglomerated charge.

Stiff Extrusion relies on heavy duty augers to create high pressures for forging materials through forming dies. As the materials are pressed through the augers and dies under high pressure and shear there is a lot of particle breakdown that occurs within the material mass. The particle breakdown that occurs is unique to the Stiff Extrusion process and the affect is to produce a particle size distribution that improves the "extrudability" of the material. This high pressure and shear has the added benefit of intensively mixing the materials to a high degree of homogeneity. The most unique aspect to Stiff Extrusion is the use of vacuum. The combination of high auger pressure and vacuum de-airing results in a tougher agglomerated product, even in the green state, that can withstand multiple handling operations. The stiff extrusion process typically requires less binders and additives.

This step involves subjecting the material to an intense vacuum prior to extrusion in order to remove all of the compressible air from the material before it is compressed under high pressure. The end result is a much stronger and more durable agglomerated product. This feature is not expensive although the effect adds great benefit. It should be noted that the application of vacuum requires specialized vacuum sealing mixers - Pug Sealers. The volumetric dosing is applied for the charge components and is being implemented by the automatic loader, which creates the stockpile of the charge mix (but the cement), taking each single component from separate stockpiles located at the open air areas. Charge mix is also being fed to the hopper of the briquetting line by loader where from it goes through the homogenizing mixers to the extruder.

The blended material is loaded into a Steele 88E Even Feeder at the start of the process. Output from the feeder

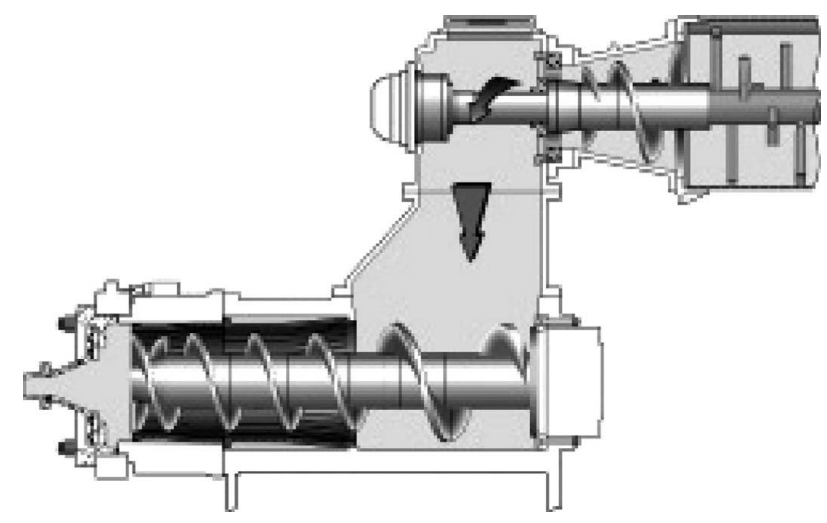

Fig. 1. Stiff extrusion under the vacuum process diagram.

goes into the primary mixer, a Steele Model 25A Pug Sealer. These "Pug Sealer" mixers have a high pressure screw section which intensively mixes the materials. A second 25A Pug Sealer is next in line. This machine sits on top of the extruder and not only mixes intensively but also seals for vacuum (Fig. 1).

The mix enters the vacuum chamber being partially agglomerated and due to the presence of a high vacuum inside the chamber and removal of the air and moisture these agglomerates immediately crumbles to isolated particles that drop down at the blades of the extruder's auger. The vacuum is maintained throughout the working volume of the extruder. The application of the vacuum has its result in the lower content of the binder required for the BREX to achieve the design level of the mechanical strength when compared with the traditional briquetting technologies. For BF applications the average amount of Portland cement is less than $6-8 \%$ of the BREX mass against $10-12 \%$ usually required for the vibropressing technology.

A model 25B Vacuum Extruder completes the process by pressing the material mixture through the extrusion dies under high pressure and vacuum. The green BREX from the extruder are directed into a covered stockpile where they cure of at least 3 days. Due to the high pressure of the extrusion and the mixture's deairing in the vacuum the green BREX at the exit of the extruder dies have a dense structure, high initial strength and plasticity. This allows the transportation and the stockpiling of the BREX for strengthening without any fines generation. The general layout of the industrial extrusion agglomeration line is given in Fig. 2.

\subsection{Raw Materials}

The main components of the brex are - steel-making (LD; Linz-Donau process sludge) and BF dust, iron ore fines. The binder and plasticizer are the Portland cement (OPC53) and the Bentonite. Phase compositions of these substances are given in Table 1.

Chemical composition of the BREX is given in Table 2.

Grains sizes of these component's particles are as follows: iron ore fines $-80-82 \%$ of particles smaller than 1 $\mathrm{mm}$; BF dust $-75-7 \%$ of particles smaller than $0.149 \mathrm{~mm}$; LD sludge $-43-47 \%$ of particles smaller than $0.149 \mathrm{~mm}$. For Portland cement the typical particles surface area is larger than $4000 \mathrm{~cm}^{2} / \mathrm{g}$. Bentonite particles - up to $75-90 \%$ smaller than $0.074 \mathrm{~mm}$. Chemical composition of the binder and plasticizer are given in Table $\mathbf{3}$. 


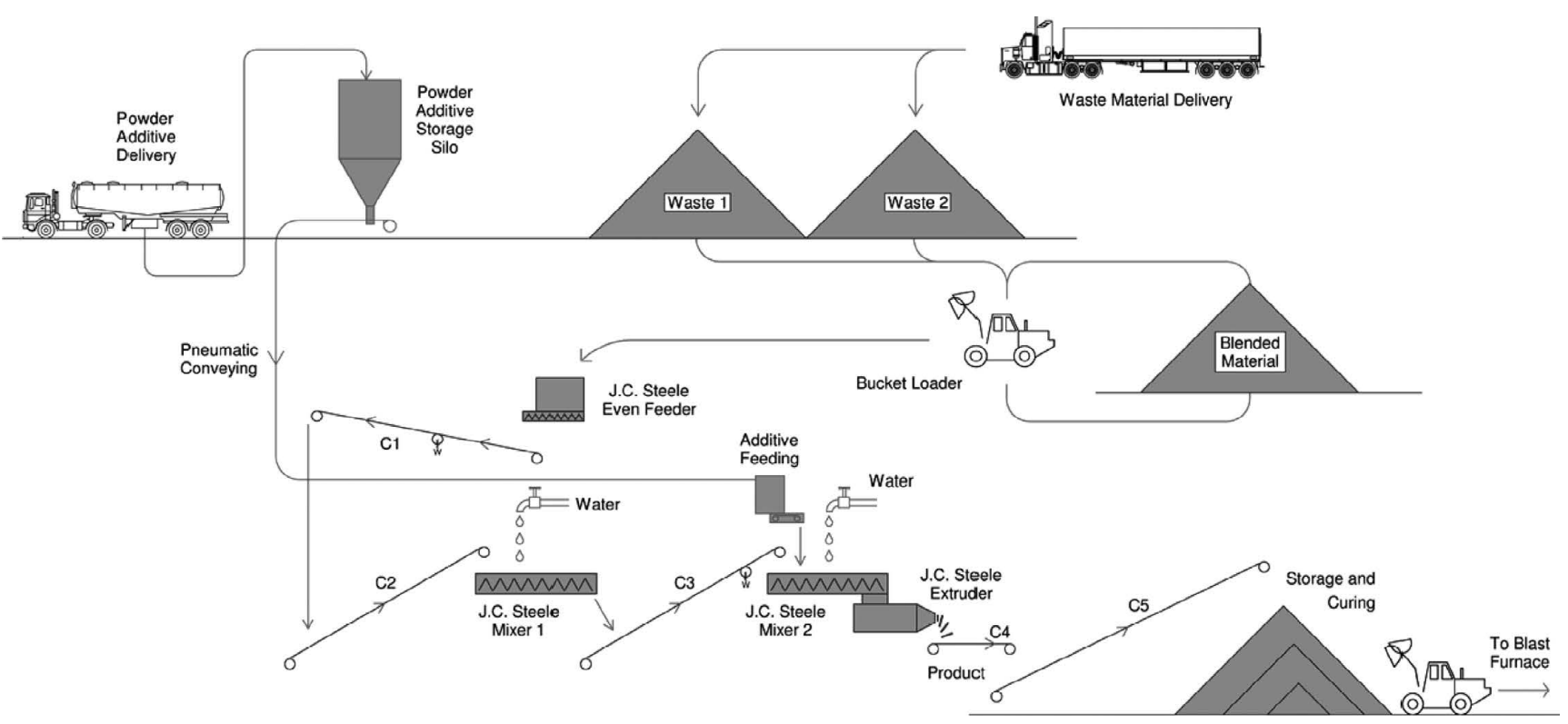

Fig. 2. General layout of the industrial extrusion agglomeration line with capacity of 20 tons per hour for blast furnace.

Table 1. Phase composition of the BREX components.

\begin{tabular}{|c|c|c|}
\hline BREX component & Main phases & Minor phases \\
\hline Iron ore fine & Hematite & $\begin{array}{l}\text { Goethite, Gibbsite, } \\
\text { Kaolin, Pyroxene }\end{array}$ \\
\hline Blsat furnace dust & $\begin{array}{l}\text { Magnetite, Hematite, } \\
\text { Graphite }\end{array}$ & $\begin{array}{l}\text { Wustite, Quartz, } \\
\text { Dicalcium aluminate }\end{array}$ \\
\hline LD sludge & Magnetite, Wuestite & Wollastonite, calcite \\
\hline
\end{tabular}

Table 2. Chemical composition of the BREX components. $\%$

\begin{tabular}{lccccccccc}
\hline $\begin{array}{l}\mathrm{BREX} \\
\text { components }\end{array}$ & $\mathrm{Fe}_{2} \mathrm{O}_{3} / \mathrm{FeO}$ & $\mathrm{SiO}_{2}$ & $\mathrm{CaO}$ & $\mathrm{MgO}$ & $\mathrm{Al}_{2} \mathrm{O}_{3}$ & $\mathrm{TiO}_{2}$ & $\mathrm{C}$ & $\mathrm{Fe}_{\text {total }}$ \\
\hline $\begin{array}{l}\text { Iron ore } \\
\text { fines }\end{array}$ & 78.5 & 5.6 & - & - & 5.4 & 0.8 & - & 53.5 \\
$\begin{array}{l}\text { Blast furnace } \\
\text { dust }\end{array}$ & 51.5 & 6.3 & 4.9 & 0.2 & 5.1 & - & 30.5 & 35.6 \\
LD sludge & 87.5 & 0.6 & 9.5 & 1.2 & 0.3 & - & - & 64.0 \\
\hline
\end{tabular}

Table 3. Chemical composition of the binder (Portland cement) and plasticizer (Bentonite).

\begin{tabular}{lcc}
\hline & & \\
\hline Elements & Portland cement OPC53 & Bentonite \\
\hline $\mathrm{CaO}$ & 63.2 & 0.8 \\
$\mathrm{SiO}_{2}$ & 20.5 & 58.4 \\
$\mathrm{Al}_{2} \mathrm{O}_{3}$ & 4.5 & 12.6 \\
$\mathrm{Fe}_{2} \mathrm{O}_{3}$ & 4.2 & 10.6 \\
$\mathrm{MgO}$ & 2.1 & 0.3 \\
$\mathrm{~K}_{2} \mathrm{O}+\mathrm{Na}_{2} \mathrm{O}$ & 0.6 & 4.4 \\
$\mathrm{SO}_{3}$ & 2.6 & - \\
$\mathrm{LOI}$ & 1.5 & 9.4 \\
\hline
\end{tabular}

\subsection{BREX Physical Properties and Cold Compressive Strength}

We have selected the BREX of the following composition for the cold compressive strength (CCS) testing: $47.2 \% \mathrm{LD}$ sludge, $28.3 \%$ BF dust, $18.9 \%$ iron ore fines, $4.7 \%$ Portland cement and $0.9 \%$ Bentonite. Chemical composition of the

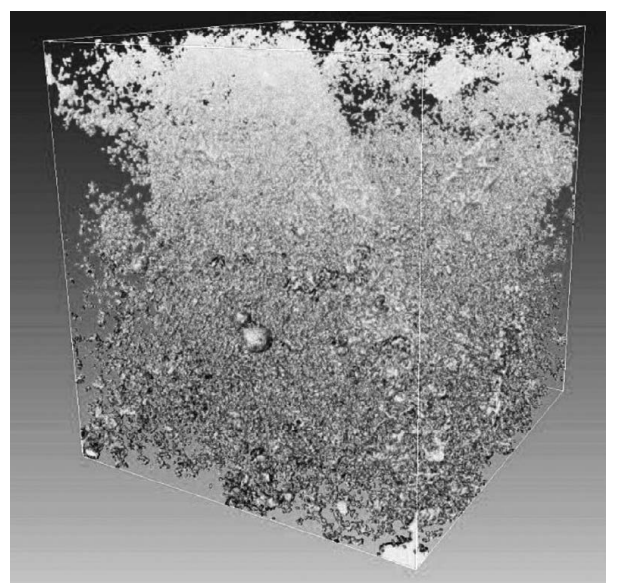

Fig. 3. Distribution of the pores with the sizes larger than $100 \mu \mathrm{m}$.

BREX after curing: $\mathrm{Fe}_{\text {total }}-43-48 \%$; $\mathrm{CaO} 11-13 \%$; $\mathrm{SiO}_{2} 7.2-$ 7.7\%; $\mathrm{Al}_{2} \mathrm{O}_{3}-4.30-5.9 \%$; $\mathrm{MgO} 2.9-3.9 \%$; LOI (hydrated water + carbon) $11-11.9 \%,\left(\mathrm{CaO} / \mathrm{SiO}_{2}\right)=1.4$. Distribution of these main components inside the BREX body was discovered to be very uniform. Their concentrations in the "core" and in the "shell" of the BREX were as follows (\%): $\mathrm{Fe}_{\text {total }}-45.11$ and 45.25; $\mathrm{CaO}-12.59$ and 12.96; $\mathrm{SiO}_{2}-7.68$ and 7.26; $\mathrm{Al}_{2} \mathrm{O}_{3}-5.16$ and 5.01; $\mathrm{MgO} 3.53$ and 3.70. Cement and Bentonite were blended in the dry state manually (Portland cement is $75 \%$ and Bentonite is $25 \%$ ) and added to the mixture before the Pug Sealer. This combined binder's share in the BREX varies from 6 to $8 \%$. For the chosen BREX samples we have measured daily: CCS, apparent density and porosity. Compressive strength was measured on a "Tonipact 3000" (Germany) in accordance with the standard DIN 51067. Cylindrical samples sizes for testing were: diameter $32.6 \mathrm{~mm}$ and height $60 \mathrm{~mm}$. Density was measured using scales Metler (USA).

Apparent porosity was measured according to DIN 51056. We have also applied X-ray computed high resolution computed tomography system Phoenix V|tome|X S 240 (General Electric, USA) in order to investigate the macro pores with the sizes larger than $100 \mu \mathrm{m}$. Figure 3 shows this 
Table 4. Values of physical properties of the BREX during strengthening.

\begin{tabular}{cccc}
\hline $\begin{array}{c}\text { Strengthening } \\
\text { duration, days }\end{array}$ & $\begin{array}{c}\text { Apparent } \\
\text { porosity, } \%\end{array}$ & $\begin{array}{c}\text { Density, } \\
\mathrm{g} / \mathrm{cm}^{3}\end{array}$ & $\begin{array}{c}\text { Cold compressive } \\
\text { strength, } \mathrm{kg} / \mathrm{cm}^{2}\end{array}$ \\
\hline 1 & 31.5 & 2.42 & 24 \\
2 & 25.4 & 2.66 & 45 \\
3 & 32 & 2.43 & 63 \\
4 & 27 & 2.44 & 52 \\
5 & 27.2 & 2.45 & 56 \\
6 & 26.2 & 2.45 & 57 \\
7 & 26.8 & 2.46 & 59 \\
8 & - & - & 75 \\
9 & - & - & 80 \\
\hline
\end{tabular}

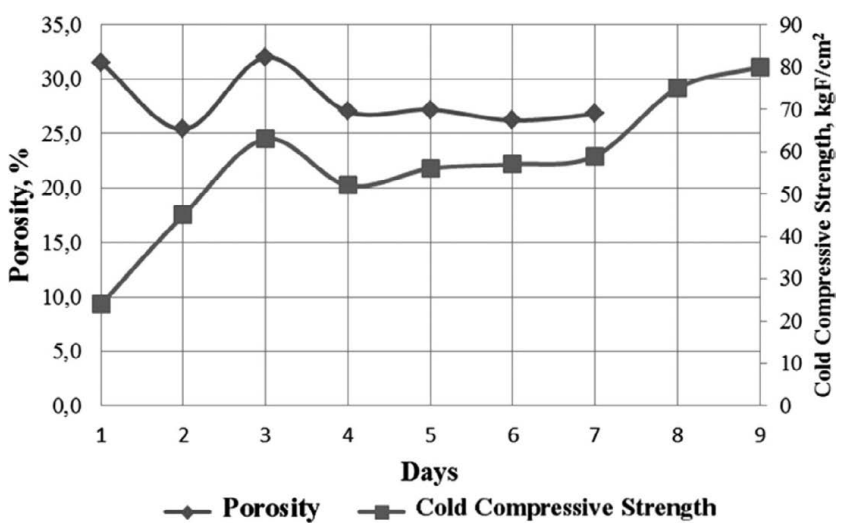

Fig. 4. Porosity and cold compressive strength during strengthening.

distribution to be sufficiently uniform thus promoting for the reducibility.

The measurement results for the apparent porosity and CCS are listed in Table 4 and illustrated by Fig. 4.

The strengthening curve has a local maximum on day three followed by the day of the strength loss and then by its final growth. The BREX compressive strength value on the day three is about $84 \%$ of its value after a week of strengthening. Almost the same is the character of the apparent porosity change except the very first day of the strengthening. Reduction of the porosity value is obviously connected with the Bentonite swelling leading to the filling of the pore space.

Samples of the BREX kept their integrity during the compressive and tensile splitting tests on the third day of curing exhibiting the viscous-plastic behavior. Despite the almost complete development of cracks during the splitting test on the third day of curing both halves of the BREX continued to be coupled. Compressive and tensile splitting tests on the day seven showed complete loss of the viscous-plastic destruction.

Such effect of the non-monotonic strengthening of briquette on the cement binder with the presence of local maximum of the strength accompanied by the viscous-plastic destruction under the external load has not been previously experienced and has not been described in the literature. In the described phenomenon the significant is the fact that the cement-bentonite composite binder changed the behavior of the BREX reducing the probability of its brittle fracture.

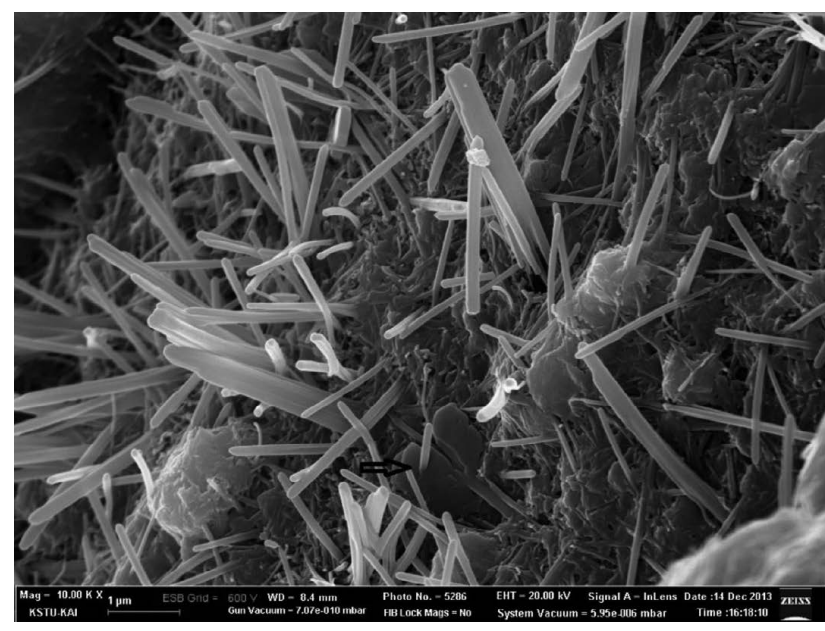

Fig. 5. Needle-like particles of cement (Ettringit) in the BREX surrounded by the bentonite flakes. SEM image (magnification $10000)$.

In our view, this BREX behavior is due to the properties of the cement-bentonite binder and is the result of creation of the coagulation structure in the cement-bentonite-water system leading to modifications of the properties of the binder. The driving force of the creation of such structures is the attraction of the negatively charged particles of bentonite to positively charged particles of Portland cement, leading to very rapid mutual coagulation of particles and to the formation of the structure, with the weighed particles of cement. Hydrating cement particles are being gradually covered by impermeable shells of the flake type particles of bentonite. The amount of adsorbed bentonite particles is proportional to the activity of cement. In the process of hydration the cement particles increase in volume, which leads to the tension and disrupt the integrity of bentonite membrane and to water penetration inside the cement particles, leading to their further hydration and to the increased adsorption of bentonite. Gradually this coagulation structure will collapse as a result of coagulating action of calcium ions and will be replaced by a structure of hardening cement stone. The remains of this structure can be illustrated by Fig. 5 obtained by the Scanning Electronic Microscopy (SEM) with the help of AURIGA ${ }^{\circledR}$ CrossBeam $^{\circledR}$ workstation (Carl Zeiss) combined with the energy dispersing spectrometer INCA X-Max. Reduced strength, observed on the third day after the peak, can be explained by the destruction of structures. Further increase in strength is fully controlled by the cement hydration.

The effect we found can have the practical value, comprised in the possibility to utilise the BREX on cementbentonite binder as a component of the charge of metallurgical furnaces on the third day of drying under natural conditions, thus leading to the significant reduction of the required storage size of finished BREX.

Another distinctive feature of the BREX is that they have a considerable length at the exit from the extruder's die. Following transportation via conveyors and subsequent reloading and stacking, the final length of the extrusion product is, usually, not more than two-to-three times its diameter. The mechanism of this fragmentation has been explained by Bizhanov et $a l^{6}{ }^{6}$ and is related with the bending of the elon- 
Table 5. Iron ore and BREX metallization and reducibility comparison.

\begin{tabular}{ccccc}
\hline $\begin{array}{c}\text { Temperature, } \\
{ }^{\circ} \mathrm{C}\end{array}$ & $\begin{array}{c}\mathrm{Fe}_{\text {met }} \\
\text { (Iron ore/BREX), \% }\end{array}$ & $\begin{array}{c}\mathrm{Fe}_{\text {total }} \\
\text { (Iron ore/BREX), \% }\end{array}$ & $\begin{array}{c}\text { Metallization } \\
\text { (Iron ore/BREX), \% }\end{array}$ & $\begin{array}{c}\text { Reducibility } \\
\text { (Iron ore/BREX), \% }\end{array}$ \\
\hline 1000 & $2.16 / 14.20$ & $67.48 / 60.50$ & $3.20 / 23.50$ & $35 / 48$ \\
1100 & $12.69 / 20.96$ & $69.52 / 61.70$ & $18.25 / 33.97$ & $52 / 62$ \\
1200 & $17.65 / 30.36$ & $70.25 / 63.70$ & $25.10 / 47.66$ & $61 / 72$ \\
1300 & $30.33 / 44.74$ & $73.3 / 65.60$ & $41.30 / 68.20$ & $65 / 80$ \\
1400 & $53.75 / 47.04$ & $80.79 / 67.46$ & $66.53 / 69.70$ & $82 / 88$ \\
1500 & $84.25 / 79.22$ & $90.40 / 80.87$ & $93.20 / 97.95$ & $93 / 99$ \\
\hline
\end{tabular}

gated BREX under their own weight at the exit of the extruder's die leading to the formation of the zones of stress concentration. Finite element simulation process of fragmentation of the elongated BREX was made with the use of Simulia Abaqus software system. Maximum stress zones and the areas of the fracture initiation have been identified. In case when the fixed length of the BREX will be required these extruders are usually equipped with the cutters.

\section{BREX Reducibility and Hot Strength Mechanism}

In order to better understand the behavior of the BREX in $\mathrm{BF}$ we have compared their reducibility with that of the iron ore. For this purpose we have used the following testing procedure. A hollow alumina tube having length $1000 \mathrm{~mm}$, outside diameter $85 \mathrm{~mm}$ and inside diameter $75 \mathrm{~mm}$ makes the test chamber. Weights of the BREX and iron ore samples were taken before and after their smelting at $1300^{\circ} \mathrm{C}$ for 30 minutes. BREX and iron ore samples are placed in graphite crucible inside of alumina crucible covered by coke breeze having size $1-5 \mathrm{~mm}$ throughout the diameter engulfing the graphite crucible completely. Thickness of the coke breeze layer is $25 \mathrm{~mm}$. Then it is blocked by perforated plug from both sides and is covered by the insulation. Water-cooled metallic clamps are fitted in both sides of alumina tube. Vacuum pump is connected in one of the clamp along with air supply connected with flow meter. Before staring the heating, the inside chamber of the alumina tube is evacuated up to $0.5 \mathrm{mbar}$. The furnace was switched on with a heating rate of $10^{\circ} \mathrm{C} /$ minute and when the temperature reached $800^{\circ} \mathrm{C}$ air supply was started at a rate of 10 liters /minute till the completion of the test. Both BREX and iron ore samples were fired from $1000^{\circ} \mathrm{C}$ to $1500^{\circ} \mathrm{C}$ for 2 hours in step of $100^{\circ} \mathrm{C}$.

Reducibility was calculated based on the oxygen loss calculations. Metallic Fe and metallization degree were evaluated. Total and metallic Fe contents, metallization and reducibility values of iron ore and BREX samples are given in Table 5.

It follows from these data that the BREX shows better metallization and reducibility in comparison with the iron ore fines which also means that they will show also better values when compared with the lumpy ore since the reducibility of the iron ore depends strongly on the lump size. ${ }^{7)}$ The reason for this is evidently related with the presence of the carbon in the BF sludge which promotes for better carbothermic reduction due to the close contact of the iron oxides and the carbon. This carbon is represented mainly by the coke breeze. Another reason for the BREX good reducibility is related with the dynamics of changes of porosity
Table 6. BREX* properties at different temperatures.

\begin{tabular}{cccc}
\hline $\begin{array}{c}\text { BREX } \\
\text { temperature, }{ }^{\circ} \mathrm{C}\end{array}$ & $\begin{array}{c}\text { Apparent } \\
\text { porosity } \%\end{array}$ & $\begin{array}{c}\text { Density } \\
\left(\mathrm{gm} / \mathrm{c}^{3}\right)\end{array}$ & $\begin{array}{c}\text { Reducibility } \\
\%\end{array}$ \\
\hline Cold BREX & 25.8 & 2.60 & - \\
500 & 33.66 & 2.67 & - \\
1000 & 37.36 & 2.81 & 9.6 \\
1100 & 37.28 & 2.61 & 12.5 \\
1200 & 46.87 & 2.56 & 78.5 \\
1300 & 29.71 & 3.08 & 80.1 \\
1400 & 22.6 & 3.19 & 85.4 \\
\hline
\end{tabular}

*-not cured BREX

Table 7. The phase composition of the BREX at different temperatures.

\begin{tabular}{lrrrr}
\hline Phase (mass share, $\%) /$ temperature, ${ }^{\circ} \mathrm{C}$ & 950 & 1000 & 1300 & 1400 \\
\hline Hematite $\left(\mathrm{Fe}_{2} \mathrm{O}_{3}\right)$ & 22.1 & 18.6 & $\mathrm{n} / \mathrm{o}$ & 4.2 \\
Magnetite $\left(\mathrm{Fe}_{3} \mathrm{O}_{4}\right)$ & 47.0 & 49.2 & 2.3 & 16.6 \\
Wustite $(\mathrm{FeO})$ & 10.7 & 3.4 & 24.8 & 34.5 \\
$\alpha$ - $\mathrm{Fe}$ & $\mathrm{n} / \mathrm{o}$ & $\mathrm{n} / \mathrm{o}$ & 31.2 & 12.0 \\
Gehlenite $\left(\mathrm{Ca}_{2} \mathrm{Al}_{2} \mathrm{SiO}_{7}\right)$ & 3.8 & 5.4 & 16.0 & 11.9 \\
Larnite $\left(\beta-\mathrm{Ca}_{2} \mathrm{SiO}_{4}\right)$ & 16.4 & 23.4 & 17.1 & 15.2 \\
Calcium ferrite $\left(\mathrm{CaFe}_{2} \mathrm{O}_{4}\right)$ & $\mathrm{n} / \mathrm{o}$ & $\mathrm{n} / \mathrm{o}$ & $\mathrm{n} / \mathrm{o}$ & 2.6 \\
Dicalcium ferrite $\left(\mathrm{Ca}_{2} \mathrm{Fe}_{2} \mathrm{O}_{5}\right)$ & $\mathrm{n} / \mathrm{o}$ & $\mathrm{n} / \mathrm{o}$ & 8.7 & 3.1 \\
Quartz $\left(\mathrm{SiO}_{2}\right)$ & $\mathrm{n} / \mathrm{o}$ & $\mathrm{n} / \mathrm{o}$ & $\mathrm{n} / \mathrm{o}$ & $\mathrm{n} / \mathrm{o}$ \\
Calcite $\left(\mathrm{CaCO}_{3}\right)$ & $\mathrm{n} / \mathrm{o}$ & $\mathrm{n} / \mathrm{o}$ & $\mathrm{n} / \mathrm{o}$ & $\mathrm{n} / \mathrm{o}$ \\
\hline
\end{tabular}

during heating

Table 6 shows how the not cured BREX apparent porosity, density and reducibility vary with the temperature of the firing under the reduction atmosphere. The porosity values remain at sufficiently high level up to $1200-1300^{\circ} \mathrm{C}$ which strongly contributes to the BREX reducibility.

The phase composition of the BREX samples fired during 2 hours at different temperatures has been determined by ARL 9900 XRF series with integrated XRD capability (Japan). The results are given in Table 7 .

Using these date we have investigated the mechanism of the hot strengthening of the BREX under the reduction atmosphere. The specially prepared samples of the BREX reduced during 2 hours at different temperatures were analyzed with the help of the Leica DFC300 FX Digital Color Camera. Figure 6 shows different stages of the BREX 

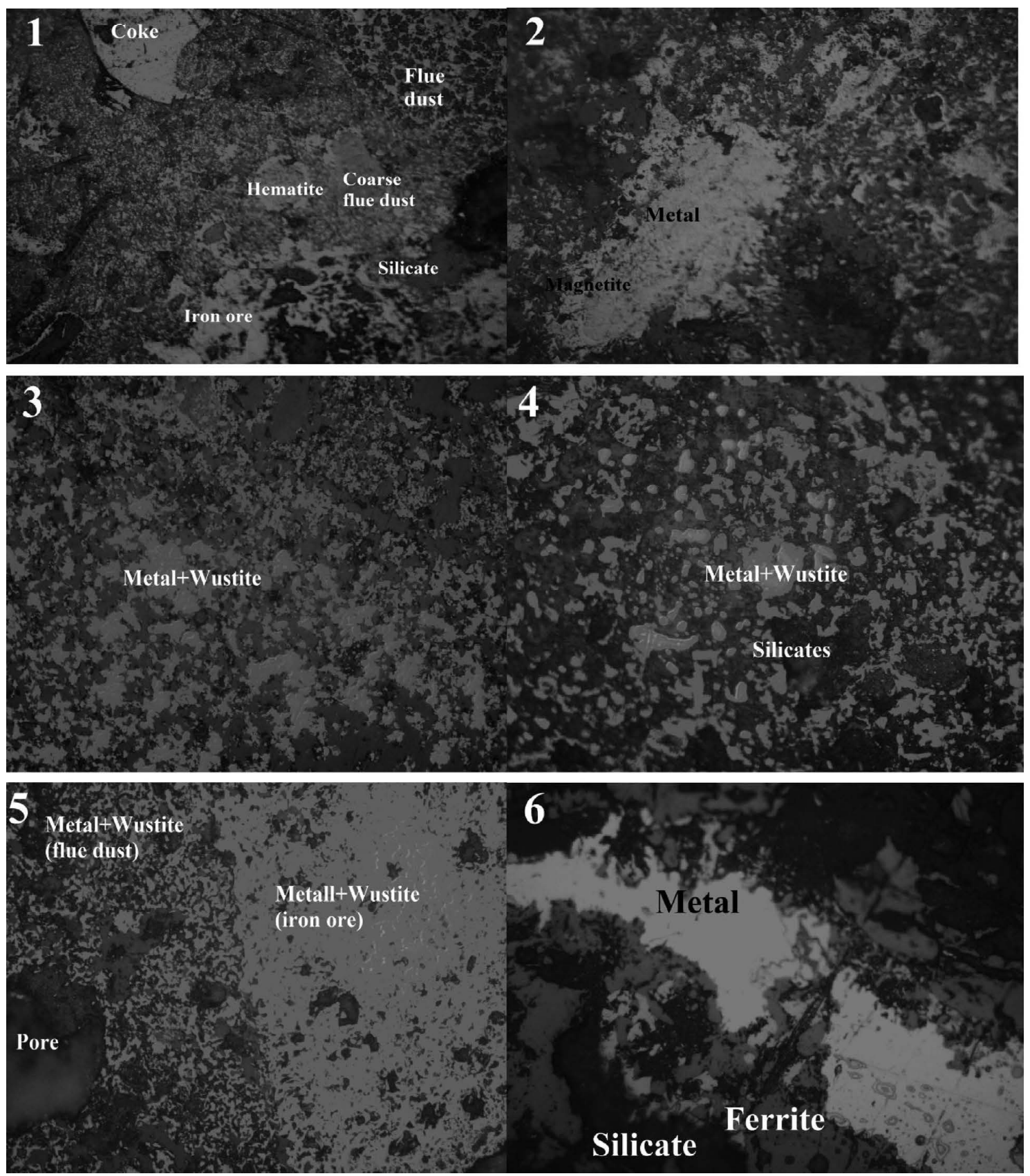

Fig. 6. Optical microscopy of the BREX strengthening during heating under the reduction atmosphere. $1-950^{\circ} \mathrm{C} ; 2-$ $1000^{\circ} \mathrm{C} ; 3-1100^{\circ} \mathrm{C}$, BREX shell region; $4-1300^{\circ} \mathrm{C} ; 5-1300^{\circ} \mathrm{C}$ (another view); 6-1 $400^{\circ} \mathrm{C}$. Magnification 200

strengthening (magnification 200).

It follows from these photos that the sintering of the grains starts at $\mathrm{T}=1000^{\circ} \mathrm{C}$. At $\mathrm{T}=1100^{\circ} \mathrm{C}$ the crust is being formed by sintered grains on the surface of the BREX. This helps to strengthen the shell of the BREX and to support the BREX. Inside the BREX the further sintering is taking place at $\mathrm{T}=1300^{\circ} \mathrm{C}$. We can witness at this temperature that iron ore grains reduce faster than those of the LD sludge and BF dust due to the higher activity of the "virgin" substance in comparison with the substances which had already underwent high temperature treatment. ${ }^{8)}$ The concentration of the Gehlenite (sorosilicate) increases whereas the concentration of the island silicate Larnite decreases at this temperature. These both silicates are known to exhibit good binding properties at the presence of free $\mathrm{CaO}$ and $\mathrm{MgO}$ which are present in the LD sludge and in the BF dust. ${ }^{9)}$ All these substances create a new binder which supports the BREX at high temperatures during its reduction and metallization. Worth to mention that the presence of the Larnite and Gehlenite has been discovered during the investigation of the reduction behavior of cold-bonded briquettes under simulated BF conditions. ${ }^{9)}$ The detailed investigation of the role of these silicates in the BREX strengthening will follow.

At $\mathrm{T}=1400^{\circ} \mathrm{C}$ one can see the structure of the metal surrounded by the silicates and ferrites. This mechanism coincides generally with the mechanism of the strengthening of the vibropressed briquettes described by Kurunov et al. ${ }^{10)}$ Thus the metallization of the surface layer of the agglomerated product helps to keep the integrity during its reduction with the creation of the metallic phase supported by the silicates and ferrites matrix. 


\section{Results and Discussions}

Based on the above mentioned results of the investigations it has been decided to try to achieve maximum possible share of the BREX in the charge of the industrial small-scale $\mathrm{BF}$ with the volume equal to $45 \mathrm{~m}^{3}$ (useful volume 40.01 $\mathrm{m}^{3}$ ). The BF is equipped with: skip hoist with the skip volume of $0.5 \mathrm{~m}^{3}$, double-cone charging device, and hydraulic equipment for notch service, hot blast stoves and two-stage dry gas-cleaning system (dust collector and seven modules of the bag filters). BF has eight air tuyeres and one iron notch. The furnace is cooled by external watering. Produced cast iron is immediately poured by the casting machine and slag is granulated. Cast iron and granulated slag are being shipped to the customers by trucks.

With the two shifts working schedule the extrusion line produces 200 tons of BREX per day (12 castings per day). A required amount of the washing BREX made of the manganese ore fines $(-3 \mathrm{~mm}$ size $)$ with $5 \%$ of Portland cement as the binder are also produced according to the operation schedule. The BREX in amount of 100-135 tons per day are being melted in the Blast Furnace.

The operation has started in the May 2011 with $10 \%$ of the BREX in the charge. Then this share has been gradually increasing. When working on the charge consisting of $80 \%$ of the BREX and $20 \%$ of iron ore, the coke consumption decreased by $150 \mathrm{~kg} / \mathrm{t}$ of cast iron (22\%) in the result of the decrease of the carbon content in the BREX and by the withdrawal of the charge of raw fluxes. Lowering of the BF performance by $15 \%$ while switching to the new charge with BREX was mainly due to lower iron content in this charge by $7.2 \%$ compared to the charge consisting of the iron ore and raw fluxes. Further increase of the BREX share in the charge was not possible because of the excessive increase in basicity of slags caused by the high basicity of the BREX in the result of the LD sludge presence.

During the development of the BF regimes with this new type of briquetted charge we had to go to the new lower level of the stockline in the furnace due to the difficulties encountered in the dry gas cleaning system. Gradual increase in the share of the BREX in BF charge resulted in a lowering of the temperature of the furnace top gas and increased its moisture content. As a result the bag filters get clogged with the wetted dust and their regeneration by the reverse pressure pulses has not reached the positive effect. Stockline lowering helped to increase the furnace top gas temperature and the bag filters sticking stopped. Lowering of the stockline virtually had no impact on the performance of BF mainly due to the iron oxides of the BREX are being reduced by the dispersed carbon contained in them. At the same time it has been decided to increase the iron ore fines share in the BREX from $9.45 \%$ up to $18.9 \%$ which has also contributed to the better BF performance due to the mentioned above better sintering and higher value of the activity of the "virgin" iron ore substance when compared with the sludge and dust which already have undergone high-temperature processing once.

For more than 2.5 years the BF has worked successfully with the charge containing $80 \%$ of the BREX and is now (August 2014) for already ten months this BF works with the $100 \%$ briquetted charge.
Successful practice of the BREX utilization as the primary, and then the only component of the BF charge became possible due to their good metallurgical properties corresponding with the requirements of the ironmaking throughout the life cycle of the BREX from the moment they exit the extruder's die and till the formation of cast iron in the blast furnace. Indeed, on the way from the extruder to stockpile and then to the ready goods warehouse the BREX do not generate fines. Negligible amount of fines can only be generated during the BREX loading by the fork-lift trucks. This allows to avoid the fines screening before the charging the BREX to the BF without any damages for blast furnace. Skips with the BREX do not contain any fines and their pouring from the bunker to skip and from skip to charging device of $\mathrm{BF}$ is not accompanied by the dust generation.

In the BF when lowering from the top the BREX do not collapse and preserve its integrity up to the softening and further melting in cohesion zone. The results of the wide set of the high-temperature testing of the BREX of different composition in reducing atmosphere confirm this conclusion. ${ }^{11)}$ All the BREX when heated at a speed of $500^{\circ} \mathrm{C} / \mathrm{h}$ up to $1150^{\circ} \mathrm{C}$ and a half-hour excerpt at that temperature and then cooled in an inert atmosphere kept its shape ${ }^{\circ} \mathrm{C}$.

The BF operation parameters with different shares of the BREX in the charge are given in Table 8.

Table 8. BF operation parameters.

\begin{tabular}{|c|c|c|c|}
\hline $\begin{array}{l}\text { Blast furnace operation } \\
\text { parameters }\end{array}$ & $\begin{array}{l}100 \% \\
\text { iron ore }\end{array}$ & $\begin{array}{c}80 \% \\
\text { BREX }\end{array}$ & $\begin{array}{l}100 \% \\
\text { BREX }\end{array}$ \\
\hline \multicolumn{4}{|l|}{ Consumption, $\mathrm{kg} / \mathrm{t}$ : } \\
\hline iron ore & 1500 & 372 & 372 \\
\hline BREX & - & 1425 & 1960 \\
\hline Limestone & 150 & - & - \\
\hline dolomite & 144 & - & 29 \\
\hline scrap & 132 & - & - \\
\hline Quartzite & - & - & 13 \\
\hline washing Mn ore BREX & - & 19 & 75 \\
\hline Coke & 680 & 530 & 490 \\
\hline $\begin{array}{l}\text { Iron content in the fluxed } \\
\text { charge*,\% }\end{array}$ & 57.6 & 50.4 & 45.5 \\
\hline Furnace capacity, t/m³ в сут. & 1.9 & 1.62 & 2.0 \\
\hline Blast temperature, ${ }^{\circ} \mathrm{C}$ & 925 & 900 & 1000 \\
\hline Tuyere pressure, $\mathrm{kg} / \mathrm{cm}^{2}$ & 0.5 & $0.34-0.38$ & $0.38-0.42$ \\
\hline \multicolumn{4}{|l|}{ Pig iron chemistry, \%: } \\
\hline $\mathrm{Si}$ & $1.0-1.8$ & $1.0-1.5$ & $0.8-1.1$ \\
\hline $\mathrm{Mn}$ & 0.2 & $0.4-0.5$ & $0.7-0.8$ \\
\hline $\mathrm{C}$ & $3.8-4.0$ & $3.75-3.90$ & $3.80-3.95$ \\
\hline $\mathrm{S}$ & $0.050-0.060$ & $0.038-0.050$ & $0.038-0.042$ \\
\hline Pig iron temperature, ${ }^{\circ} \mathrm{C}$ & $1380-1440$ & $1400-1450$ & $1410-1450$ \\
\hline \multicolumn{4}{|l|}{ Slag chemistry, $\%$ : } \\
\hline $\mathrm{CaO}$ & 34.86 & 33.12 & $38-39$ \\
\hline $\mathrm{SiO}_{2}$ & 31.98 & 30.23 & $30.0-32.0$ \\
\hline $\mathrm{Al}_{2} \mathrm{O}_{3}$ & 23.87 & 17.98 & $16.0-18.8$ \\
\hline $\mathrm{MgO}$ & 9.46 & 9.48 & $8.0-9.5$ \\
\hline $\mathrm{FeO}$ & 1.01 & 1.26 & $0.6-1.15$ \\
\hline
\end{tabular}

*-without $\mathrm{CO}_{2}$ and fluxes 
As it is seen, despite the high specific heat loss, due to the small size of the blast furnace, and low blast temperature, the consumption of coke in the BF at $100 \%$ of BREX does not exceed $500 \mathrm{~kg} / \mathrm{t}$, which corresponds to the modern high-efficiency furnaces with iron content of $58-59 \%$ in charge with a temperature of $1200^{\circ} \mathrm{C}$ and with the blast overpressure of gas on furnace top equal to180-250 $\mathrm{kPa}$. This is the consequence of the self-reducing nature of the BREX (due to the presence of carbon in BF dust) and of their basicity, providing the necessary basicity of BF slag. The latter allowed eliminating use of the limestone. Additions of the quartzite and dolomite were applied in order to adjust the slag basicity and magnesia content in the slag. As a result the coke consumption for the $100 \%$ of the BREX in the charge has fallen on about $200 \mathrm{~kg} / \mathrm{t}$ compared to the $100 \%$ rich iron ore charge operation of blast furnace. It can also be seen that $\mathrm{Si}$ content in pig iron has approached the level typical for large blast furnaces. The total self-cost of the BREX is less than 11 USD for one ton (including all expenses and the binder cost) which helps to this BF to operate with positive economic efficiency.

\section{Conclusions}

From the results of more than three years of the industrial cats iron production by the small-scale BF with the BREX as the major and an exclusive charge component it follows that:

(1) Stiff vacuum extrusion provides for the metallurgical properties of the BREX which meet the requirements of the BF process with a lower level of the binder content compared with traditional briquetting technologies.

(2) BREX have sufficient mechanical strength to with- stand the transportation and further handling, including stockpiling and further feeding to the BF without generation of the fines.

(3) Application of the combination of the Portland cement and the Bentonite can lead to the local maximum of the BREX mechanical strength on third day of its curing.

(4) BREX have sufficient porosity to ensure their good reducibility.

(5) Strengthening of the BREX during their heating under the reduction conditions comprises the creation of the metallized shell on their surface, sintering of the ironcontaining particles and further creation of the metallicc phase surrounded by the silicates and ferrites.

(6) BREX can be used as the major or exclusive charge component of the small scale blast furnaces sufficiently improving their economic attractiveness.

\section{REFERENCES}

1) B. M. Ravich: Briquetting in Ferrous and Non-Ferrous Metallurgy, Metallurgy, Moscow, (1975), 232.

2) A. G. Astakhov, A. I. Machkovskyi, A. I. Nikitin, N. V. Fedorovskyi: Handbook of Sinter Plant Worker, Tekhnika, Kyiv, (1964), 448.

3) A. M. Bizhanov: BREX, Trademark Certificate No. 498006, (2013).

4) R. B. Steele: Proc. of 23rd Biennial Conf., IBA, USA, (1993), 205.

5) Y. K. Dalmia, I. F. Kurunov, R. B. Steele and A. M. Bizhanov: Metallurgist, (2012), No. 3, 39.

6) A. M. Bizhanov, I. F. Kurunov, N. M. Durov, D. V. Nushtaev and S. A. Ryzhov: Metallurgist, 56 (2012), 489.

7) O. A. Esin and P. V. Geld: Physical Chemistry of Pyrometallurgic Processes, Part 1, Mettallurgisdat, Moscow, (1962), 671.

8) Ya. E. Geguzin: Physics of Sintering, Nauka, Moscow, (1967).

9) A. Kempainen, M. Iljana, E.-P. Heikkinen, T. Paananen, O. Mattila and T. Fabritius: ISIJ Int., 54 (2014), 1539.

10) I. F. Kurunov, T. Ya. Malysheva and O. G. Bolshakova: Metallurgist, (2007), No. 10, 41

11) I. F. Kurunov, A. M. Bizhanov, D. N. Tikhonov and N. R. Mansurova: Metallurgist, (2012), No. 6, 44. 